\title{
1 A crocodylian-style cloaca in a non-avialan dinosaur
}

2

3 Phil R. Bell ${ }^{1, *}$, Michael Pittman ${ }^{2, *}$, Thomas G. Kaye ${ }^{3}$ \& Christophe Hendrickx ${ }^{4}$

$5 \quad{ }^{1}$ School of Environmental and Rural Science, University of New England, Armidale, NSW

6 2351, Australia; email: pbel123@une.edu.au

$7 \quad{ }^{2}$ Vertebrate Palaeontology Laboratory, Division of Earth and Planetary Science, The

8 University of Hong Kong, Pokfulam, Hong Kong SAR, China; email: mpittman@ @ku.hk

$9 \quad{ }^{3}$ Foundation for Scientific Advancement, Sierra Vista, Arizona, USA; email:

10 tom@tomkaye.com

$11{ }^{4}$ Unidad Ejecutora Lillo, CONICET-Fundación Miguel Lillo, Miguel Lillo 251, San Miguel

12 de Tucumán 4000, Tucumán, Argentina; email: christophendrickx@ gmail.com

13 *corresponding authors; these authors contributed equally

\section{Abstract}

16 Our knowledge of the reproductive biology of dinosaurs covers a range of aspects, from

17 brooding behaviour to nesting style and the timing of sexual maturity. Yet, the basic anatomy

18 and function of the cloaca in non-avialan dinosaurs remains unknown. Here, we describe the outer morphology of the only known non-avialan dinosaur cloaca, preserved in an exceptional specimen of the early-diverging ceratopsian dinosaur Psittacosaurus. We clarify

21 the position of the cloaca with respect to the ischia and caudal vertebrae and document the scales immediately adjacent to the abdomen and tail. We find that the cloaca is from a nearsexually mature subadult individual and is most similar to the cloaca of crocodylians, to the exclusion of lepidosaurians and birds. However, the sex of SMF R 4970 could not be determined as the cloaca and the rest of the specimen does not yield any sexually dimorphic 
information. This study highlights the ongoing role of exceptional specimens in providing rare soft tissues that help to bridge longstanding gaps in our knowledge of the basic biology of dinosaurs and other extinct reptiles.

\section{Introduction}

31 The reproductive biology of extinct non-avialan dinosaurs is rarely interpreted from the fossil record. To date, exceptionally well-preserved remains and the extant phylogenetic bracket (EPB; [1]) have clarified details including their brooding behaviour, nesting style and timing of sexual maturity [2-7]. However, the anatomy and function of the cloaca has continued to remain elusive. In archosaurian and lepidosaurian reptiles, the cloaca forms the common opening of the digestive and urogenital tract and consists of a series of chambers - the coprodeum, urodeum, and proctodeum—separated by muscular sphincters, and which terminates in the vent [8-10]. As a result, it serves as the passage for digestive and urinary wastes, transmission of the male copulatory organ, and the passage of eggs or live young in addition to a variety of less obvious functions such as salt and temperature regulation [11].

41 Nearly 70 years ago, Alfred Romer predicted that the cloaca in extinct archosaurs was positioned within the proximal tail region where haemal arches are absent [1]. Here, we provide confirmation of Romer's original prediction based on an exquisitely-preserved specimen of an early-diverging ceratopsian dinosaur, Psittacosaurus sp., discovered from the Early Cretaceous Jehol Group of northeastern China [12]. This specimen, known for its exquisite coloured epidermal structures and elongate caudal monofilaments [12-14], preserves for the first time the outer morphology of the cloaca in a non-avialan dinosaur. 
51 The right femur of Senckenberg Museum Frankfurt (SMF) R 4970 is $~ 140 \mathrm{~mm}$ long. This is

52 similar to the femoral lengths of $P$. lujiatunensis Institute of Vertebrate Paleontology and

53 Paleoanthropology (IVPP) V12617 (138mm) and V18344 (145mm), Liaoning

54 Paleontological Museum (LPM) R00128 (135mm) and R00138 (144mm) and Peking

55 University Vertebrate Paleontology (PKUVP) V1053 (149mm) and V1056 (135mm) which

56 belong to $\sim 6-7$ year old subadults (see Table 1 and Fig. 5 of Erickson et al. [15] and

57 Supplementary Table S2 of Zhao et al. [16]). This age is just shy of sexual maturity and at

58 the beginning of the exponential growth phase (see Table 1 and Fig. 5 of Erickson et al. [15]

59 and Supplementary Table S2 of Zhao et al. [16]). The femoral length of SMF R 4970 is

60 therefore the closest match to a nearly sexually mature subadult (see Table 1 and Fig. 5 of

61 Erickson et al. [15] and Supplementary Table S2 of Zhao et al. [16]). Thus, the configuration

62 and morphology of the cloaca in SMF R 4970 and its surrounding osteological correlates had

63 not yet reached its most developed form or full sexual maturity.

64

65 The cloaca and its surrounding scales and bones 
66

\section{7}

68

69

70

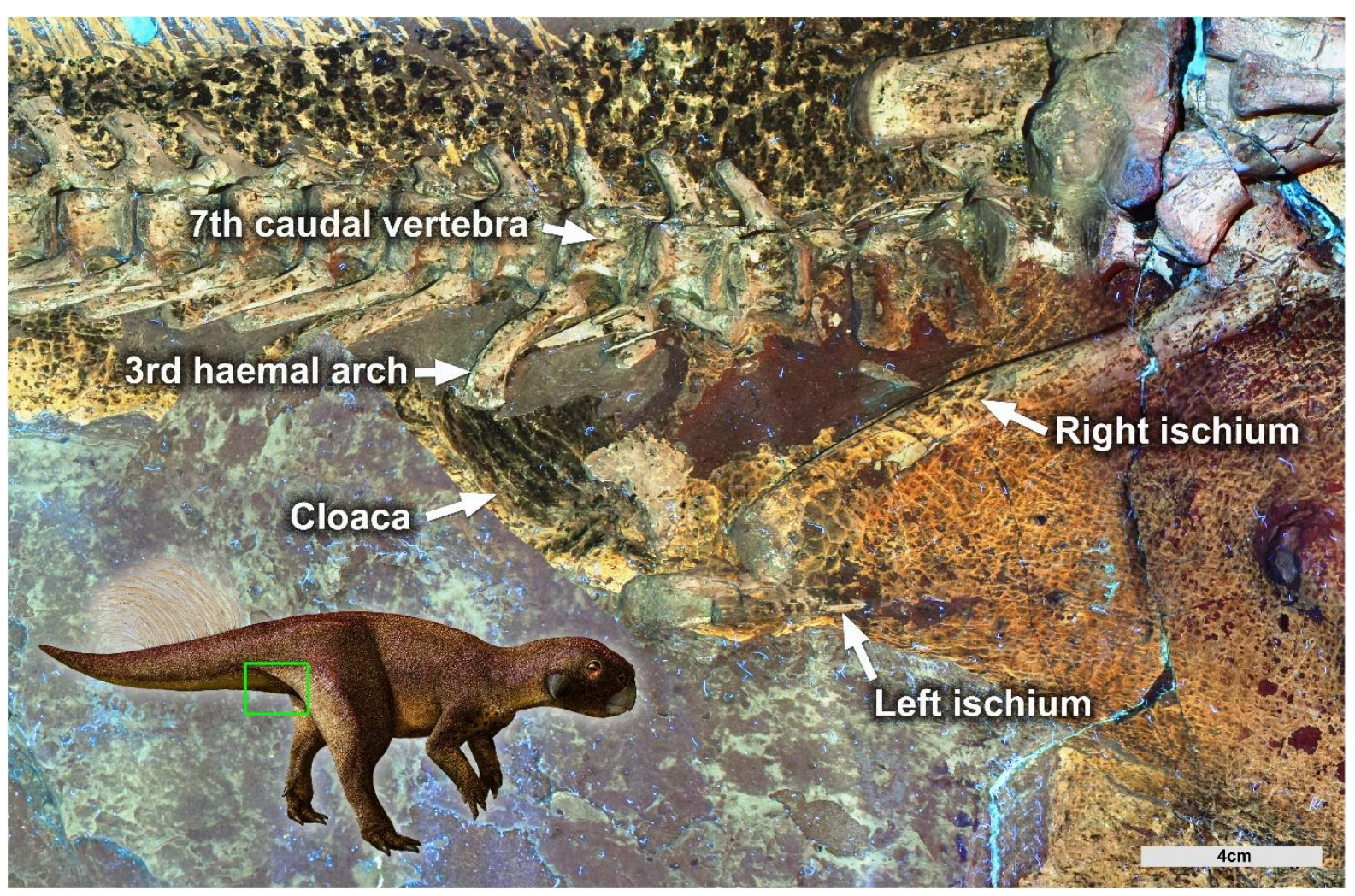

Figure 1. Cloacal region of the ceratopsian dinosaur Psittacosaurus under Laser-

Stimulated Fluorescence (LSF). The cloaca soft tissue is the blackish mottled ovoid area

preserved in the region between the ischia and the third haemal arch in specimen SMF R

4970 from the Early Cretaceous Jehol Group of northeastern China. Scale is $4 \mathrm{~cm}$. Life

reconstruction with green box showing the position of the LSF image. Image Credit: Julius T.

Csotonyi (image used with permission).

Immediately posterior to the ischiadic symphysis is the fleshy aperture (or vent) of the cloaca

(Figs. 1, 2). Since SMF R 4970 is preserved lying on its back, both the left and right sides of the cloaca are visible, although the right side is better exposed (Fig. 1). The vent itself is longitudinally oriented ( $2 \mathrm{~cm}$ long) and surrounded on either side by darkly pigmented tissue. This appears to lie flush with the ventral parts of the abdomen and tail (i.e. it does not form a cloacal protuberance). The darker cloaca is clearly differentiated, from the lightercoloured surrounding integument (Fig. 2). 


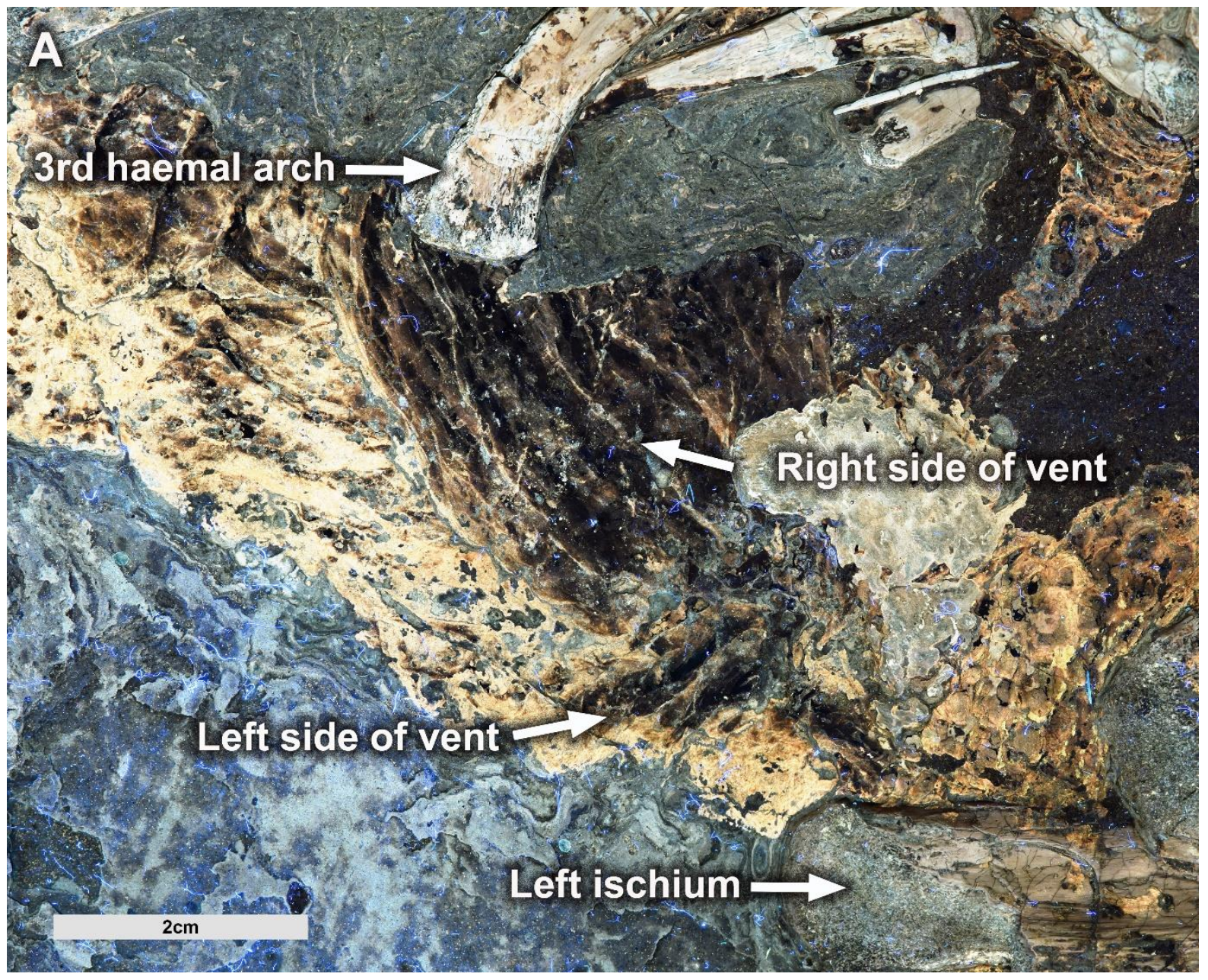




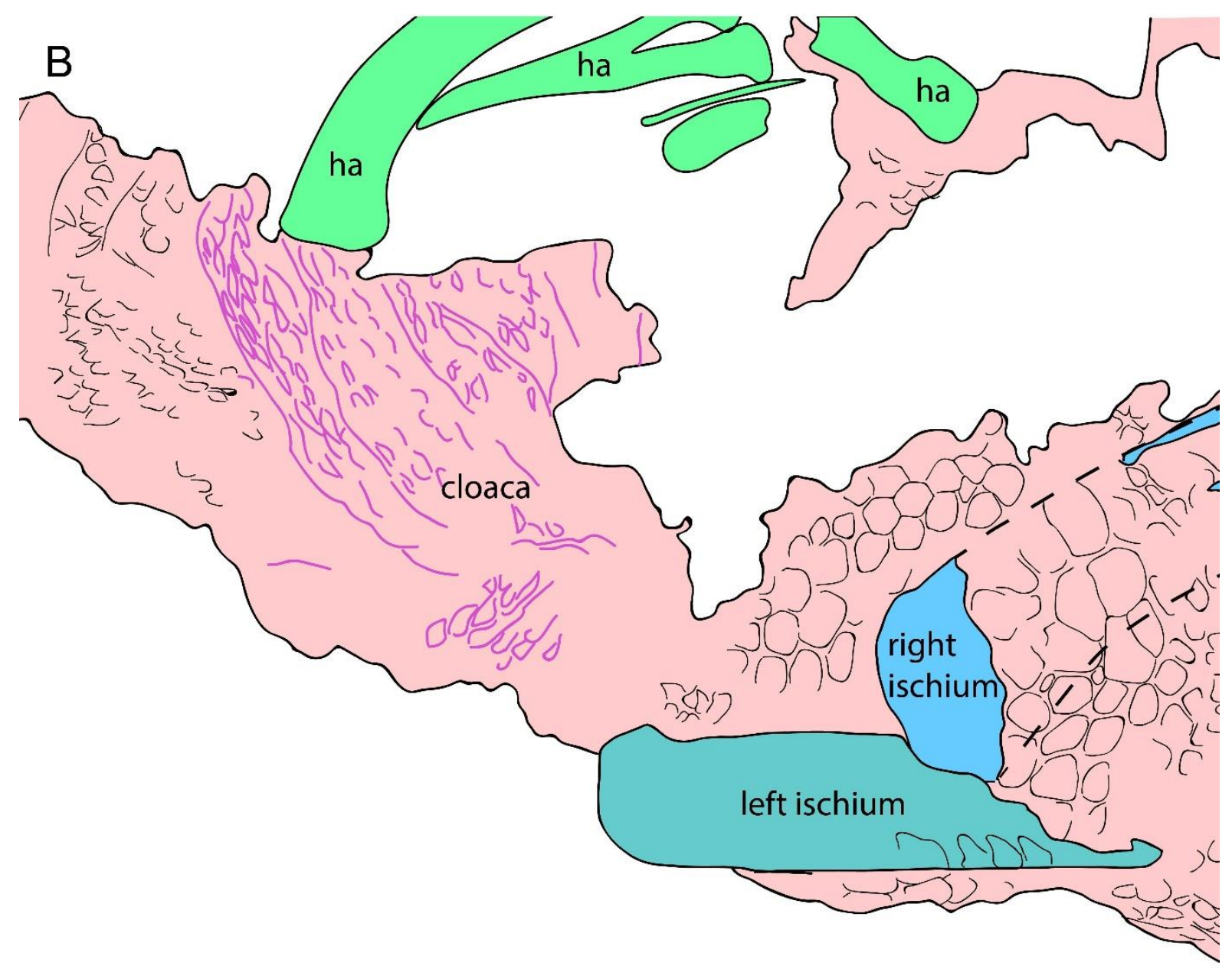

Figure 2. Close up of the cloaca of Psittacosaurus sp. SMF R 4970. A. The right side of the longitudinally presented vent is better exposed. The outer morphology of the cloaca is darkly pigmented compared to adjacent areas of the ventrum. Scale bar is $2 \mathrm{~cm}$. B. Interpretative drawing of the cloacal region showing the integument in red shading and the details of the cloaca in pink line colour. Haemal arches (ha) marked in lime green and left and right ischia coloured in dark green and blue, respectively. Scale bar is $1 \mathrm{~cm}$.

The darkly-pigmented tissue surrounding the vent is wrinkled, the creases of which are parallel and radiate from the vent in a posterolateral direction $(\sim 3 \mathrm{~cm}$ long $)$ towards the ventral tip of the third haemal arch (Fig. 2). Unlike the other haemal arches, the third haemal arch, which articulates with the posteroventral corner of the $7^{\text {th }}$ caudal vertebra, is subvertical 
94 and strongly bowed (anteriorly concave) (Fig. 1). In contrast, the remaining haemal arches are all straight and strongly posteroventrally oriented (Fig. 1). The first and second haemal arches are also peculiar in being roughly half the length of the third arch, although the first arch appears to be broken into two adjacent lengths (Fig. 1). The scales covering the darkly pigmented tissue surrounding the vent are also distinct from those on the abdomen and tail: scales surrounding the vent are relatively large, roughly lenticular $(\bar{x}$ length $=3.4 \mathrm{~mm})$, the long axes of which are oriented parallel to the surrounding wrinkles (Figs. 1, 2). Further along the tail, the ventral integument consists of distinct vertical bands (arranged transversely in life) of typically rounded-quadrangular scales, which range from 1.7 to $3.3 \mathrm{~mm}$ in height (Fig. 1). The same transverse banding of quadrangular scales also occurs on the abdomen, anterior to the ischiadic symphysis (Fig. 1).

\section{Discussion}

\section{Cloaca anatomy and biological implications}

The Psittacosaurus specimen SMF R 4970 is unique among non-avialan dinosaurs in preserving the outer morphology of the cloaca, including the vent. SMF R 4970 demonstrates unequivocally that the genitals were housed internally in Psittacosaurus and likely in all other non-avialan dinosaurs, as in all known animals with a cloaca. For comparison with the cloaca of SMF R 4970, a representative sample of snakes, lizards, birds, and crocodylians were observed in the collections of the University of New England's Natural History Museum. The internal anatomy of the cloaca in lepidosaurians, crocodylians, and birds differs substantially and is accompanied by modifications to the external appearance of the vent. The vent in living sauropsids can be divided into three main types [17]: transversely opening (snakes and lizards), longitudinally opening (crocodylians), or round/square (birds).

18 The integumentary covering across these three types differs accordingly. In snakes, the 
transverse vent is covered by one or two cloacal scales that are modifications of the broad ventral scales present elsewhere on the underbelly. The condition in lizards is highly variable but the vent is always transverse and accompanied by a variable number of cloacal scales that may or may not differ from the surrounding scales. Among birds, the area immediately surrounding the cloaca is naked, bearing neither scales nor feathers. In crocodylians, the longitudinal vent is surrounded by elliptical-to-polygonal scales that radiate and increase in size from the vent itself. This rosette arrangement of cloacal scales is distinct from the transverse rows of comparatively large quadrangular scales that extend along the ventral surfaces of the abdomen and tail. Thus, the gross morphology of the vent in Psittacosaurus, which combines a longitudinally opening vent with a rosette pattern of cloacal scales and transverse rows of quadrangular ventral scales, most closely matches that of crocodylians. The position of the vent is also distinctive in Psittacosaurus. Romer [1] remarked that

131 the cloaca opens immediately posterior to the distal ischia in all reptiles; however, it may be supported by an ossified hypoischium that projects posteriorly from the ischial symphysis in some lizards (see [18] and references therein). In many lizards, the vent is typically positioned just posterior to the joint between the first and second caudal vertebrae and is never further than the third caudal vertebra [18]. Birds on the other hand have highly modified tails that terminate in a pygostyle (e.g. [19]) and therefore do not provide a suitable analogue for comparisons. Matching Romer's [1] prediction, the vent, in Psittacosaurus,

138 opens just posterior to the distal ischia and in line with the joint between the fifth and sixth 139 caudal vertebrae. The crocodilian-like vent of Psittacosaurus implies that, unlike lizards and later-

141 diverging birds, Psittacosaurus probably had a muscular, unpaired, and ventrally-positioned 142 copulatory organ (e.g. [20]) and a ureter that was decoupled from the copulatory organ [9].

143 Some birds possess a single copulatory organ, but the majority of species lack a phallus 
144 entirely [21]. Like crocodylians, birds still use internal fertilisation, which is the presumed

145 method in Psittacosaurus. Crocodylians and some early-diverging crown birds (e.g., Rhea,

146 tinamous) have a ureter that opens into the coprodeum, whereas in later-diverging crown

147 birds, the ureter empties into the urodeum [9]. The presumably paired oviducts in

148 Psittacosaurus [22] would have opened into the urodeum as well.

149 Despite the remarkable preservation of SMF R 4970, it was not possible to determine

150 its sex. Although histological examination was not available, SMF R 4970 was not gravid,

151 and therefore unlikely to have been producing medullary bone [23]. There is no evidence of a

152 recognisable sexually dimorphic cloacal structure in SMF R 4970. A cloacal protuberance

153 temporarily develops in some birds during the breeding period, but its utility as a dimorphic

154 structure is undermined by its presence in both males and females in some species [24]. In

155 crocodylians, sex determination is entirely dependent on the inspection of the genitalia and

156 has no relationship to the external morphology of the cloaca/vent $[25,26]$. Internally, a

157 reduced first (and second) haemal arch — as in SMF R 4970 — has been suggested to identify

158 female dinosaurs based on the alleged condition in modern crocodylians $[1,27]$. However,

159 this hypothesis has no statistical support [28]. The enlarged third haemal arch was likely the

160 origin for muscles responsible for closing the cloaca (m. transversus medianus [17]). Anterior

161 haemal arches are commonly abbreviated in dinosaurs and seem to be an ancestral feature

162 based on rare early dinosaur fossils preserving this portion of the tail (e.g. Chilesaurus,

163 Eoraptor, and Tawa). Their presence in modern crocodylians suggests they might even be

164 ancestral to archosaurs pending further fossil tail discoveries. Thus, the only known record of

165 a non-avialan dinosaur cloaca has a crocodylian-style and does not show external sexually

166 dimorphic structures that can determine the sex of SMF R 4970.

167

168 Methods 
169 SMF R 4970 was photographed using Laser-Stimulated Fluorescence (LSF) performed using

170 an updated version of the methodology proposed by Kaye et al. [29] and refined in Wang et

171 al. [30]. Only a brief description of the method is provided here. A $405 \mathrm{~nm}$ violet near-UV

172 laser diode was used to fluoresce the specimen following standard laser safety protocol. Long

173 exposure images were taken with a Nikon D810 DSLR camera fitted with a $425 \mathrm{~nm}$ long-

174 pass blocking filter and controlled from a laptop using digiCamControl. Image post-

175 processing (equalization, saturation and colour balance) was performed uniformly across the

176 entire field of view in Photoshop CS6. As soft tissue details in SMF R 4970 are best visible

177 under LSF, the observations made using this technique and the resulting digital images

178 formed the basis for our descriptions. All measurements were taken using digital images

179 uploaded and calibrated in ImageJ v1.52q or Photoshop CS6. Comparative anatomy involved

180 a representative sample of snakes, lizards, birds and crocodylians, which were observed in

181 the collections of the University of New England's Natural History Museum (Armidale,

182 Australia). Computed tomography (CT) scans of a subadult male Crocodylus porosus

183 scanned and acquired by Klinkhamer et al. [31] were visualised using Dragonfly 2020.1

184 (www.theobjects.com).

\section{Acknowledgements}

187 We thank Rainer Brocke, Olaf Vogel, and Gerald Mayr (SMF) for specimen access, J. Holley

188 (UNE) for access to comparative collections, and T. Frauenfelder (UNE) for assistance with

189 Dragonfly 2020. P.R.B. was supported by an Australian Research Council Discover Early

190 Career Research Award (project ID: DE170101325). M.P. and T.G.K. are supported by a

191 RAE Improvement Fund of the Faculty of Science, The University of Hong Kong (HKU) and

192 HKU MOOC course Dinosaur Ecosystems. C.H. is supported by the Consejo Nacional de 


\section{References}

197 1. Romer, A.S. (1956). Osteology of the reptiles, (Chicago: University of Chicago).

198 2. Norell, M.A., Clark, J.M., Chiappe, L.M., and Dashzeveg, D. (1995). A nesting

199 dinosaur. Nature 378.

$2003 . \quad$ Erickson, G.M., Curry-Rogers, K., Varricchio, D.J., Norell, M.A., and Xu, X. (2007). Growth patterns in brooding dinosaurs reveals the timing of sexual maturity in nonavian dinosaurs and genesis of the avian condition. Biology Letters 3, 558-561.

4. O'Connor, J.K., Zheng, X., Wang, X., Wang, Y., and Zhou, Z. (2014). Ovarian follicles shed new light on dinosaur reproduction during the transition towards birds. National Science Review 1, 15-17.

5. Reisz, R.R., Evans, D.C., Roberts, E.M., Sues, H.D., and Yates, A.M. (2012). Oldest known dinosaurian nesting site and reproductive biology of the Early Jurassic sauropodomorph Massospondylus. Proceedings of the National Academy of Sciences 109, 2428-2433.

6. Tanaka, K., Zelenitsky, D.K., and Therrien, F. (2015). Eggshell porosity provides insight on evolution of nesting in dinosaurs. PLOS ONE 10, e0142829.

7. Tanaka, K., Zelenitsky, D.K., Therrien, F., and Kobayashi, Y. (2018). Nest substrate reflects incubation style in extant archosaurs with implications for dinosaur nesting habits. Scientific Reports 8, 1-10.

8. Gabe, M., and Saint Girons, H. (1965). Contribution a la morphologie comparée du cloaque et des glandes épidermoïdes de la region cloacale chez les lépidosauriens. Mémoires du Muséum national d'Histoire naturelle, Sér. A - Zoologie 33, 149-292.

9. Oliveira, C.A., Silva, R.M., Santos, M.M., and Mahecha, G.A.B. (2004). Location of the ureteral openings in the cloacas of tinamous, some ratite birds, and crocodilians: a primitive character. Journal of Morphology 260, 234-246.

10. Kuchel, L.J., and Franklin, C.E. (2000). Morphology of the cloaca in the estuarine crocodile, Crocodylus porosus, and its plastic response to salinity. Journal of Morphology 245, 168-176.

11. Hoffman, T.C., Walsberg, G.E., and DeNardo, D.F. (2007). Cloacal evaporation: an important and previously undescribed mechanism for avian thermoregulation. Journal of Experimental Biology 210, 741-749.

12. Mayr, G., Peters, S., Plodowski, G., and Vogel, O. (2002). Bristle-like integumentary structures at the tail of the horned dinosaur Psittacosaurus. Naturwissenschaften 89, 361-365.

13. Vinther, J., Nicholls, R., Lautenschlager, S., Pittman, M., Kaye, T.G., Rayfield, E., Mayr, G., and Cuthill, I.C. (2016). 3D camouflage in an ornithischian dinosaur. Current Biology 26, P2456-2462.

14. Mayr, G., Pittman, M., Saitta, E., Kaye, T.G., and Vinther, J. (2016). Structure and homology of Psittacosaurus tail bristles. Palaeontology 59, 793-802.

15. Erickson, G.M., Makovicky, P.J., Inouye, B.D., Zhou, C.F., and Gao, K.Q. (2009). A life table for Psittacosaurus lujiatunensis: initial insights into ornithischian dinosaur population biology. Anatomical Record 292, 1514-1521. 
16. Zhao, Q., Benton, M.J., Sullivan, C., Sander, P.M., and Xu, X. (2013). Histology and postural change during the growth of the ceratopsian dinosaur Psittacosaurus lujiatunensis. Nature Communications 4, 1-8.

17. Gadow, H. (1887). Remarks on the cloaca and on the copulatory organs of the Amniota. Philosophical Transactions of the Royal Society of London B 178, 5-37.

18. Blob, R.W. (1998). Evaluation of vent position from lizard skeletons for estimation of snout: vent length and body mass. Copeia, 792-801.

19. Felice, R.N., and O'Connor, P.M. (2014). Ecology and caudal skeletal morphology in birds: the convergent evolution of pygostyle shape in underwater foraging taxa. PLoS One 9, e89737.

20. Sanger, T.J., Gredler, M.L., and Cohn, M.J. (2015). Resurrecting embryos of the tuatara, Sphenodon punctatus, to resolve vertebrate phallus evolution. Biology Letters 11, 20150694.

21. King, A.S. (1981). Phallus. In Form and function in birds, A.S. King and J. McLelland, eds. (London: Academic Press), pp. 107-147.

22. Sato, T., Cheng, Y.N., Wu, X.C., Zelenitsky, D.K., and Hsiao, Y.F. (2005). A pair of shelled eggs inside a female dinosaur. Science 308, 375-375.

23. Bailleul, A.M., O’Connor, J., Zhang, S., Li, Z., Wang, Q., Lamanna, M.C., Zhu, X., and Zhou, Z. (2019). An Early Cretaceous enantiornithine (Aves) preserving an unlaid egg and probable medullary bone. Nature Communications, 1275.

24. Briskie, J.V. (1998). Avian genitalia. Auk 115, 826-828.

25. Brazaitis, P.J. (1968). The determination of sex in living crocodilians. Herpetological Journal 4, 54-58.

26. Webb, G.J., Manolis, S.C., and Sack, G.C. (1984). Cloacal sexual of hatchling crocodiles. Wildlife Research, 11, 201-202.

27. Larson, P. (1994). Tyrannosaurus sex. The Paleontological Society Special Publications 7, 139-156.

28. Erickson, G.M., Lappin, A.K., and Larson, P. (2005). Androgynous rex-the utility of chevrons for determining the sex of crocodilians and non-avian dinosaurs. Zoology 108, 277-286.

29. Kaye, T.G., Falk, A.R., Pittman, M., Sereno, P.C., Martin, L.D., Burnham, D.A., Gong, E.P., Xu, X., and Wang, Y. (2015). Laser-stimulated fluorescence in paleontology. PLOS ONE 10, e0125923.

30. Wang, X.L., Pittman, M., Zheng, X.T., Kaye, T.G., Falk, A.R., Hartman, S.A., and $\mathrm{Xu}, \mathrm{X}$. (2017). Basal paravian functional anatomy illuminated by high-detail body outline. Nature Communications $8,14576$.

31. Klinkhamer, A.J., Wilhite, D.R., White, M.A., and Wroe, S. (2017). Digital dissection and three-dimensional interactive models of limb musculature in the Australian estuarine crocodile (Crocodylus porosus). PLOS ONE 12, e0175079. 